\title{
Communication
}

\section{New Mussel Inspired Polydopamine-Like Silica-Based Material for Dye Adsorption}

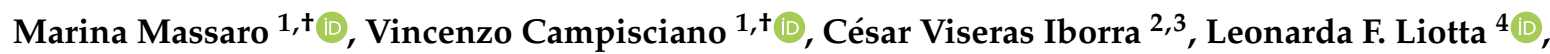 \\ Manuel Sánchez-Polo ${ }^{5}$ (D), Serena Riela ${ }^{1, *}$ and Michelangelo Gruttadauria ${ }^{1, * \mathbb{D}}$ \\ 1 Department of Biological, Chemical and Pharmaceutical Sciences and Technologies, University of Palermo \\ Viale delle Scienze, Ed. 17, 90128 Palermo, Italy; marina.massaro@unipa.it (M.M.); \\ vincenzo.campisciano@unipa.it (V.C.) \\ 2 Department of Pharmacy and Pharmaceutical Technology, Faculty of Pharmacy, University of Granada, \\ Campus of Cartuja, 18071 s/n Granada, Spain; cviseras@ugr.es \\ 3 Andalusian Institute of Earth Sciences, CSIC-UGR, Avenida de las Palmeras 4, 18100 Armilla, Granada, Spain \\ 4 Istituto per lo Studio dei Materiali Nanostrutturati (ISMN)-CNR, Via Ugo La Malfa 153, 90146 Palermo, Italy; \\ leonardafrancesca.liotta@cnr.it \\ 5 Department of Inorganic Chemistry, Faculty of Pharmacy, University of Granada, 18071 Granada, Spain; \\ mansanch@ugr.es \\ * Correspondence: serena.riela@unipa.it (S.R.); michelangelo.gruttadauria@unipa.it (M.G.); \\ Tel.: +39-091-23897546 (S.R.); +39-091-23897534 (M.G.) \\ + Equally contribution.
}

Received: 7 May 2020; Accepted: 14 July 2020; Published: 20 July 2020

check for updates

\begin{abstract}
A straightforward and economic procedure has been developed for the synthesis of a new polydopamine-like silica-based material that has been obtained by oxidation of catechol with $\mathrm{KIO}_{4}$ followed by reaction with 3-aminopropyltrimethoxysilane. All techniques adopted for characterization showed that the obtained material is rich in different functional groups and the morphological analyses revealed dimensions in the nanometric range. The hybrid material has been characterized by several techniques showing its polydopamine-like nature, and preliminary observations for dye adsorption have been reported.
\end{abstract}

Keywords: catechol; silica nanoparticles; bioinspired materials; dye adsorption

\section{Introduction}

The production of smart nanomaterials with specific responses often involves the chemical modification of surfaces with the aim to impart hydrophilic/hydrophobic, antifouling, anti-icing, photo responsive and adhesive properties to the target material.

Catecholamine chemistry, which represents the core of the mussel-inspired coating technology, has been widely exploited for modification and functionalization of surfaces [1], and in this scenario, the surface coating with polydopamine is the most appealing.

In the last few years, other polydopamine-like materials have been investigated, and the use of dopamine as starting molecule for the formation of the polymeric film coating was replaced by other catechol moiety containing compounds such as tannic acid, caffeic acid, gallic acid, and catechol, among others [2,3]. However, the use of such alternative sources of the catechol moiety require the presence of amine-based derivatives able to undergo co-polymerization processes leading to the formation of the desired polymeric coating film $[4,5]$. The so-obtained polymers can possess a series of appealing features, such as the case in which catechol was co-polymerized in the presence of polyethylenimine to give rise to a material active in the reduction of water pollution [6]. The crosslinking chemistry of catechol-based molecules with amines was investigated using propylamine and 4-methyl catechol, 
as model compounds, with the aim to shed some light on the structures of the complex mixture obtained [7]. The use of 3-aminopropyltriethoxysilane (APTES) as amine-derivative has aroused great attention due to its capacity to quickly react with hydroxyl groups present on an hydrophilic surfaces leading to a strong adhesion of the resulting coating layer on different supporting materials [8]. Silvestri et al. reported the polymerization of 5,6-dihydroxyindole-2-carboxylic acid with APTES for targeted subcellular antioxidant protection [9]. Zhou et al. used tannic acid-APTES polymer for different applications including dye adsorption, oil/water separation, and 4-nitrophenol reduction [10], or for enzyme immobilization [3]. Knorr et al. reported the use of polydopamine-APTES hybrids in coating applications [11,12]. Fu et al. described the coating of stainless steel by hydrolytic polycondensation of APTES and polymerization of dopamine [13].

The increased attention to environmental protection has to deal with a world in which large-scale production is required. In this context, textile industry represents one of the most productive sectors that has an inevitable impact on the environment with release of hazardous compounds consisting of organic dyes, such as methyl orange, rhodamine B, among others. It is therefore not surprising that different approaches have been developed for the dye-contaminated waste water treatment. Dyes sorption onto suitable materials represents one of the most advantageous techniques for dye removal due to the high efficiency of the process, energy saving, and easy recycling of sorbent material [14-16]. Therefore, it is crucial to find new sorbent materials which can be applied for removal of pollutants.

In the light of the great interest in mussel-inspired chemistry, herein we present a simple and low-cost approach for the synthesis of a polydopamine-like silica-based material by employing the easily available catechol coupled with 3-aminopropyltrimethoxysilane (APTMS) used as source of the amine moiety (PolyCat-Si). We choose catechols as source for the synthesis of polidopamine-like nanomaterials, since it is well known that they play a central role in mussel-mimicking versatility [17].

The obtained hybrid material PolyCat-Si was fully characterized and a possible structure was proposed. In addition, some preliminary results about its potential use for dyes removal were reported.

\section{Results and Discussion}

PolyCat-Si was easily obtained by reaction between catechol (>99\%, Sigma-Aldrich, Schnelldorf, Germany) and APTMS (97\%, Sigma-Aldrich, Schnelldorf, Germany). In order to form enough $o$-quinone, the oxidant $\mathrm{KIO}_{4}(99.8 \%$, Sigma-Aldrich, Schnelldorf, Germany) was added and the reaction was carried out at room temperature using carbonate buffer $(10 \mathrm{mM}, \mathrm{pH} 9.0)\left(\mathrm{K}_{2} \mathrm{CO}_{3}\right.$ and $\mathrm{KHCO}_{3}$ both $>99 \%$, Sigma-Aldrich, Schnelldorf, Germany) as solvent. The solution turned very dark in a few minutes and it was left to stir for $14 \mathrm{~h}$. To this dark solution, APTMS was added and the solution was stirred at $70^{\circ} \mathrm{C}$ for $24 \mathrm{~h}$. The $\mathrm{pH}$ value was chosen slightly lower than the $\mathrm{pK}_{\mathrm{a}}$ of propylamine (10.71) in order to have a slightly protonated amino group. This approach was chosen with the aim of limiting reactions between the amino group and o-quinones since we were interested in the reaction between trimethoxysilane moiety and aryloxy groups. After $24 \mathrm{~h}$, a brown precipitate was formed which was easily filtered, washed, and dried to give the hybrid material PolyCat-Si (Scheme 1). The first step of the synthesis involves the fast oxidation of catechol to o-quinone which can react via reverse dismutation with the starting catechol, to yield highly reactive semi-quinone radicals that can couple to form diaryl compounds. Such compounds can be further transformed/oxidised [18,19]. The mechanism between o-quinone and an amine resembles that of p-quinone and an amine [18] which can be initiated by the Michael-type addition of the amine to a carbon-carbon double bond forming an intermediate that is then isomerized to form aminocathecol which can be subsequently oxidized. This reaction mechanism has been experimentally verified recently by investigating the complex mixture of products obtained by reaction of 4-methyl catechol and propylamine in the presence of $\mathrm{NaIO}_{4}$ in $\mathrm{Na}_{2} \mathrm{CO}_{3}$ solution [7]. The main products were formed via Michael-type addition and aryloxyl-phenol coupling, with only a small fraction of products formed via Schiff base reactions [7]. In the present case, in addition to these reactions, hydrolysis and condensation of the trimethoxysilyl moiety can take place. Treatment 
of 3-aminopropyltrimethoxysilane alone in $\mathrm{KHCO}_{3} / \mathrm{K}_{2} \mathrm{CO}_{3}$ buffer solution at $70{ }^{\circ} \mathrm{C}$ in the absence of the catechol-based oxidized compounds did not give any material clearly showing the role of the latter compounds for the formation of the hybrid material, mainly via Michael-type addition reaction.

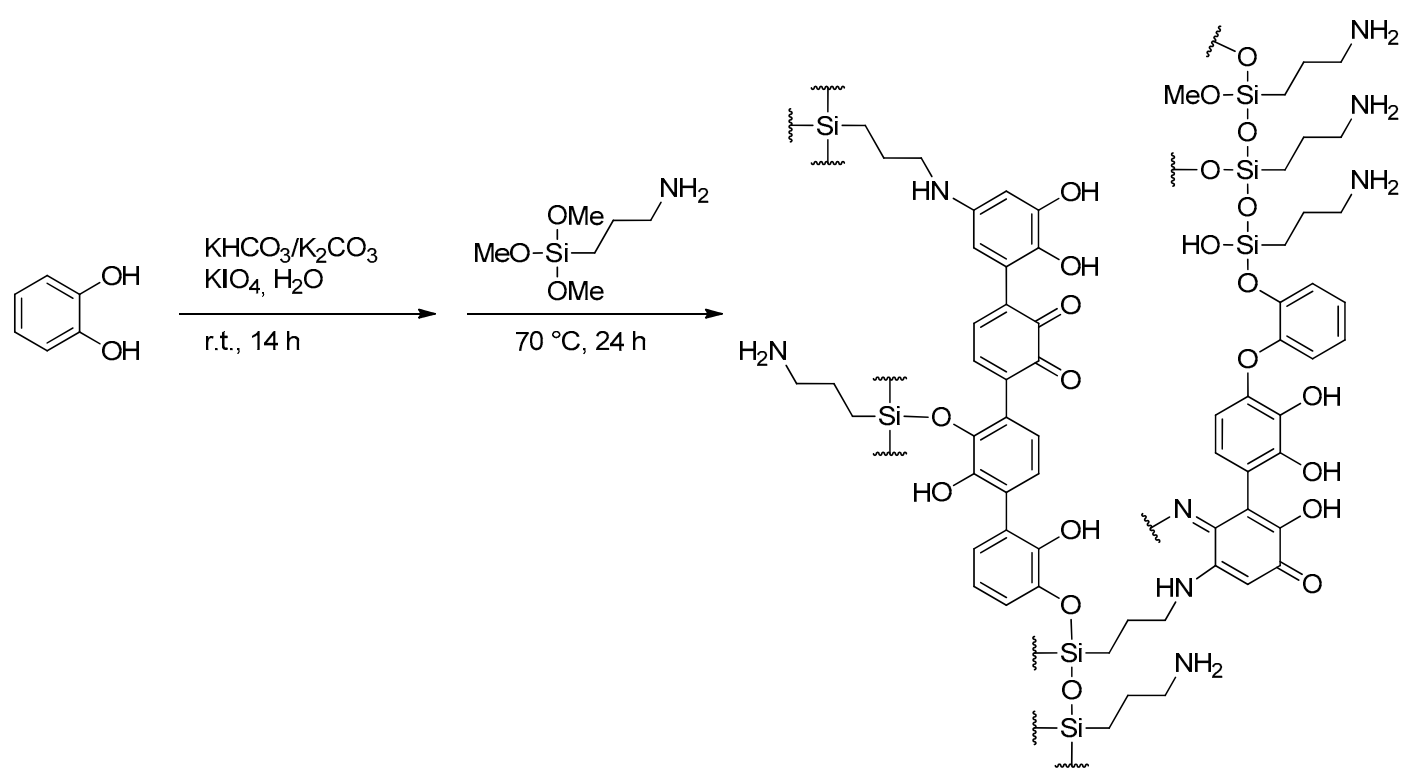

Scheme 1. Synthesis of the hybrid material PolyCat-Si. Tentative structure based on characterization data (see discussion).

The PolyCat-Si hybrid material was characterized by using several techniques confirming the presence of several functional groups as qualitatively reported in Scheme 1.

FT-IR Spectra of catechol and the PolyCat-Si were compared in Figure 1a. As it is possible to observe, the IR spectrum of PolyCat-Si shows relevant differences in comparison to that of catechol confirming the good outcome of the polymerization. In detail, the FT-IR spectrum of PolyCat-Si showed a large and broad peak centered at ca. $3350 \mathrm{~cm}^{-1}$ arising from the different stretching vibrations deriving from hydroxyl, amine groups as well as bonded and free water molecules. The peak at ca. $1600 \mathrm{~cm}^{-1}$ can be ascribed to the stretching vibration of $\mathrm{C}=\mathrm{O}$ whereas the $\mathrm{C}=\mathrm{C}$ stretching vibration of the aromatic rings generated the peak at ca. $1590 \mathrm{~cm}^{-1}$. Moreover, the $-\mathrm{NH}_{2}$ scissoring vibration mode originates the peak at ca. $1480 \mathrm{~cm}^{-1}$. The peaks at 1340 and 1260 were ascribed to the bending vibration modes of $-\mathrm{CH}_{2}$ and $\mathrm{C}-\mathrm{O}-\mathrm{H}$, respectively. Finally, the peaks centered at $1111 \mathrm{~cm}^{-1}$ and $1020 \mathrm{~cm}^{-1}$ were assigned to the symmetric stretching vibration modes of $\mathrm{C}-\mathrm{O}$ and to the $\mathrm{Si}-\mathrm{O}-\mathrm{Si}$ stretching vibrations, respectively. 


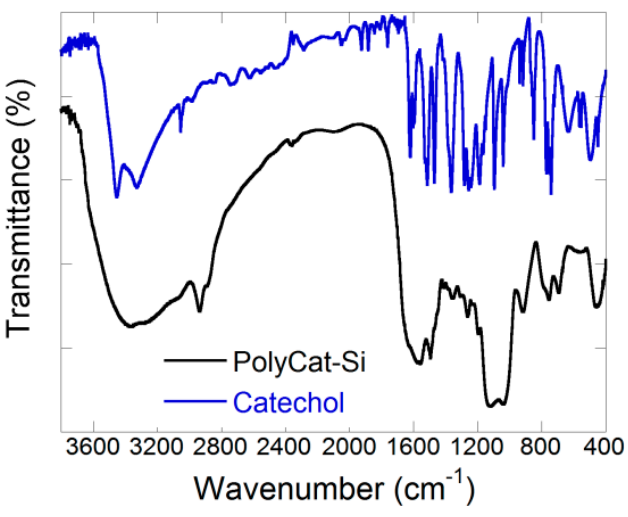

(a)

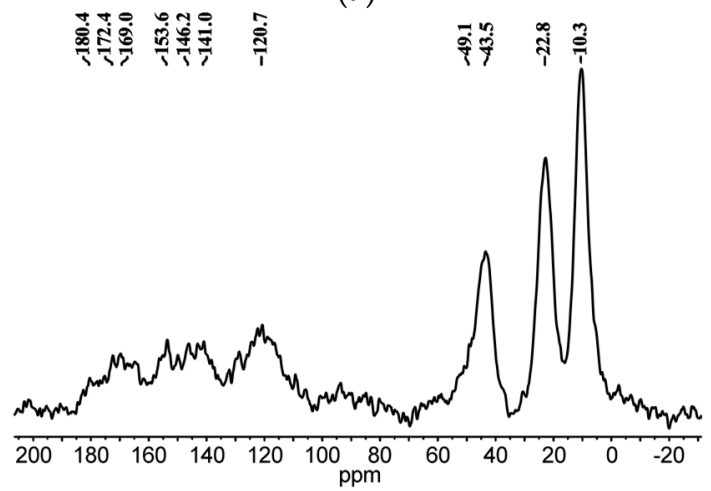

(c)

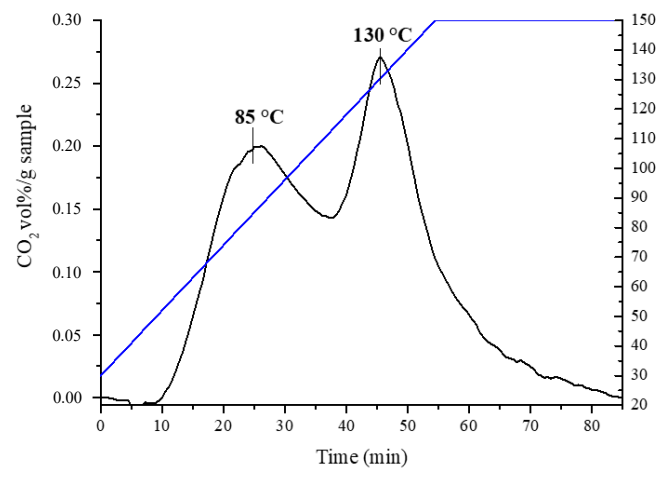

(b)

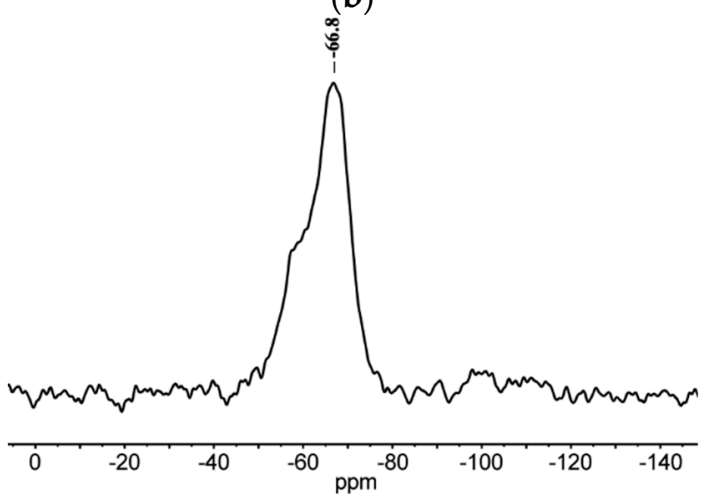

(d)

Figure 1. (a) FT-IR spectra of catechol and PolyCat-Si; (b) Temperature programmed desorption of $\mathrm{CO}_{2}$ (TPD-CO $\mathrm{CO}_{2}$ ) of PolyCat-Si; (c) ${ }^{13} \mathrm{C}$ MAS NMR spectrum; and (d) ${ }^{29} \mathrm{Si}$ NMR spectrum of PolyCat-Si.

The presence of amino groups of different nature was confirmed by temperature programmed desorption of $\mathrm{CO}_{2}$ (TPD-CO $\mathrm{CO}_{2}$ which is a useful tool to estimate the distribution of the basic sites strength and the total basicity (Figure $1 \mathrm{~b}$ ) [20-23]. The TPD- $\mathrm{CO}_{2}$ profile of PolyCat-Si, registered up to $150^{\circ} \mathrm{C}$ to avoid any degradation of the material at higher temperature (see below thermogravimetric profile, showed two $\mathrm{CO}_{2}$ desorption peaks, at ca. $90^{\circ} \mathrm{C}$ and $130{ }^{\circ} \mathrm{C}$, which can be related to different basic groups. Indeed, the occurrence of the two peaks witnesses the presence of $\mathrm{CO}_{2}$ retention sites having weak and medium basicity strength as it is related to the desorption temperature of $\mathrm{CO}_{2}$ molecules.

To further elucidate the structure of PolyCat-Si we performed some solid-state NMR and XPS characterizations.

${ }^{13} \mathrm{C}$ MAS NMR spectrum clearly shows signals related to the aminopropyl chain (Figure 1c). The shoulder at ca. $50 \mathrm{ppm}$ could be due to some residual methoxy groups linked to silicon atom. The very large signals patterns, starting from ca. $110 \mathrm{ppm}$ to ca. $180 \mathrm{ppm}$ are attributable to the complex catechol-based structures, comprising both aromatic catechol rings and $o$-quinones-based structures.

${ }^{29} \mathrm{Si}$ NMR spectrum (Figure 1d) shows a signal at $-66 \mathrm{ppm}$ due to T3 system $\mathrm{RSi}(\mathrm{OSi})_{3}$ that prove the presence of large domains of aminopropylsiloxane moiety and shoulders at ca. -57-60 ppm that could be due to the T2 systems $\mathrm{RSi}(\mathrm{OMe})-(\mathrm{OSi})_{2}$, $\mathrm{RSi}(\mathrm{OPh})-(\mathrm{OSi})_{2}$, and $\mathrm{RSi}(\mathrm{OH})-(\mathrm{OSi})_{2}$ [24].

The XPS survey spectrum for PolyCat-Si and spectra of C1s, N1s and O1s are reported in Figure 2. The hybrid material showed the presence of different functional groups (Tables 1 and 2). The full-scan XPS spectrum of PolyCat-Si (Figure 2a) revealed the presence of $C, N$, and $O$ atoms with the corresponding peaks at $284.7 \mathrm{eV}(\mathrm{C} 1 \mathrm{~s}), 399.8 \mathrm{eV}(\mathrm{N} 1 \mathrm{~s})$, and $531.7 \mathrm{eV}(\mathrm{O} 1 \mathrm{~s})$, respectively. Furthermore, representative peaks for the Si2s and Si2p are also observed, attributing the presence of the silane moieties. The XPS spectrum of $\mathrm{C} 1 \mathrm{~s}$ (Figure $2 \mathrm{~b}$ ) was deconvoluted into four surface elements corresponding $\mathrm{C}-\mathrm{Si}$ at $283.6 \mathrm{eV}, \mathrm{sp}^{2}(\mathrm{C}=\mathrm{C})$ at $284.4 \mathrm{eV}, \mathrm{C}-\mathrm{OH} / \mathrm{C}-\mathrm{N}_{(\text {arom.) }}$ at $285.8 \mathrm{eV}$, as well as $\mathrm{C}=\mathrm{O}$ at 
$287.8 \mathrm{eV}$. The O1s spectrum (Figure 2c) also confirmed the coexistence of the aforementioned species (deconvoluted into three peaks at $529.7 \mathrm{eV}, 531.1 \mathrm{eV}$, and $531.9 \mathrm{eV}$ corresponding to $\mathrm{C}=\mathrm{O}, \mathrm{O}-\mathrm{Si}$ and $\mathrm{C}-\mathrm{OH}$, respectively), as well the N1s spectrum (Figure 2d). The latter was deconvoluted into two peaks centered at 398.6, and $400.1 \mathrm{eV}$ corresponding to $-\mathrm{NH}_{2}$ and $\mathrm{C}-\mathrm{N}_{\text {(arom.) }}$, respectively. The $\mathrm{C}-\mathrm{N}$ aromatic contributions could be ascribed to the presence of amino groups directly linked to the catechol rings, whereas $-\mathrm{NH}_{2}$ aliphatic could be related to some unreacted amine tail ends according to $\zeta$-potential results (see infra).

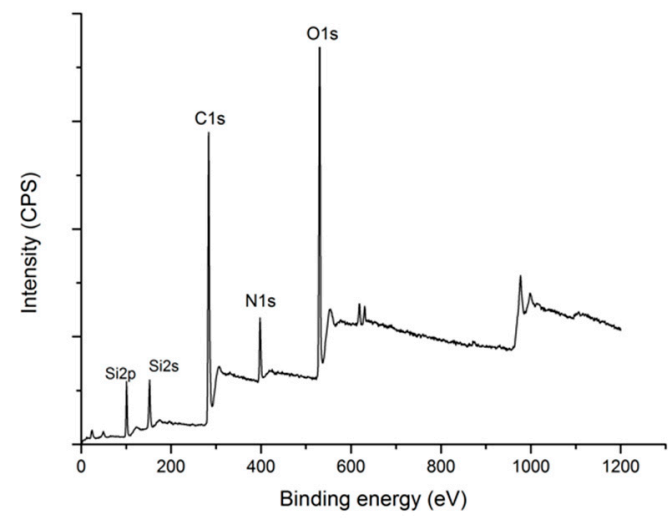

(a)

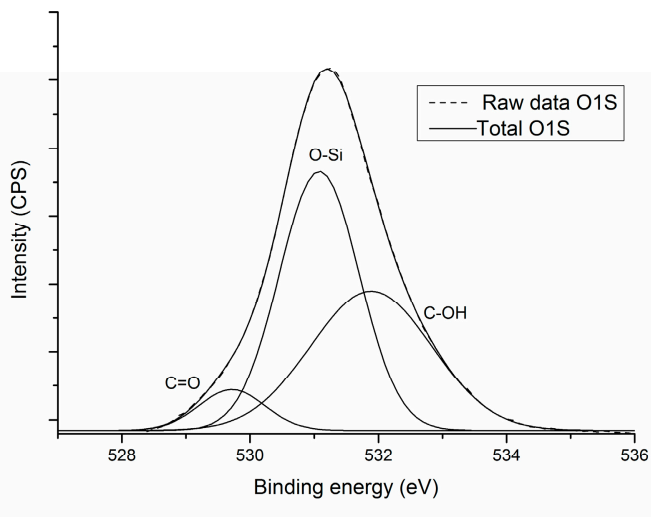

(c)

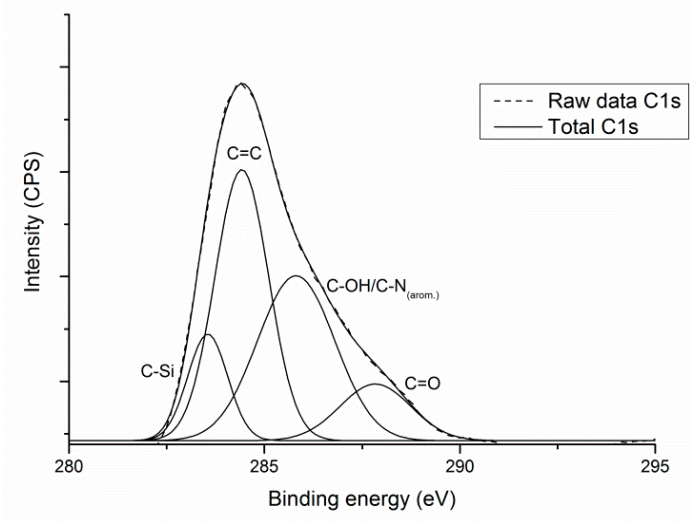

(b)

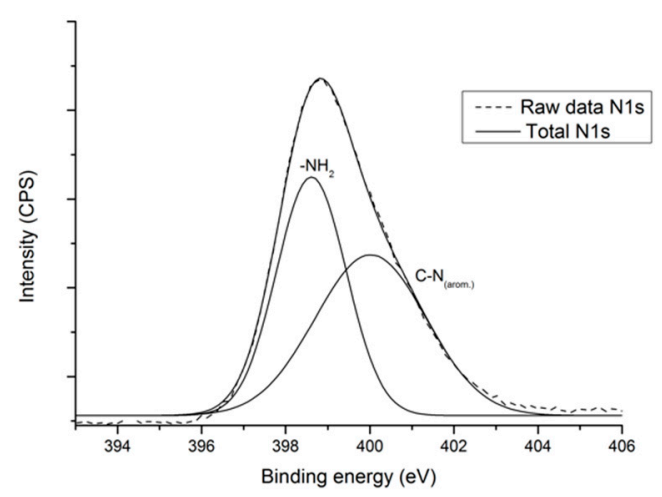

(d)

Figure 2. (a) XPS survey of PolyCat-Si; (b) deconvoluted C 1s spectrum; (c) deconvoluted O 1s spectrum; and (d) deconvoluted $\mathrm{N}$ 1s spectrum.

Table 1. Percentage of $\mathrm{Si}, \mathrm{C}, \mathrm{N}$, and $\mathrm{O}$ atoms, as determined by XPS measurements.

\begin{tabular}{ll}
\hline Atom & \% \\
\hline $\mathrm{Si}$ & 7.3 \\
$\mathrm{C}$ & 61.4 \\
$\mathrm{~N}$ & 7.4 \\
$\mathrm{O}$ & 23.6 \\
\hline
\end{tabular}

In order to study the thermal behavior of PolyCat-Si thermogravimetric analysis was performed. As it is possible to note from Figure 3a,b, PolyCat-Si showed good thermal stability, since the degradation process under air flow started at around $200{ }^{\circ} \mathrm{C}$ with light-off temperature between $300-400{ }^{\circ} \mathrm{C}$ as confirmed by the exothermic peak centred at $350{ }^{\circ} \mathrm{C}$ registered in the differential thermal analysis (DTA) curve. Pre-treatment at $100{ }^{\circ} \mathrm{C}$ showed a water content of $6.2 \%$. From the residue, we can argue that $6.36 \mathrm{mmol}$ of APTMS reacted. Considering a complete hydrolysis of the methoxy groups, $1 \mathrm{~g}$ of 
material contains ca. $750 \mathrm{mg}$ of silane and $250 \mathrm{mg}$ of catechol which means a silane:catechol molar ratio of ca. 3. The reaction was carried out with a silane:catechol molar ratio of 2.29.

Table 2. Functional groups present in the PolyCat-Si obtained by the deconvolution of XPS spectra.

\begin{tabular}{cc}
\hline Functional Groups & Abundance (\%) $^{\mathbf{a}}$ \\
\hline $\mathbf{C}$ & \\
\hline $\mathrm{C}-\mathrm{Si}$ & 12 \\
$\mathrm{C}=\mathrm{C}$ & 41 \\
$\mathrm{C}-\mathrm{OH} / \mathrm{C}-\mathrm{N}_{(\text {arom. })}$ & 11 \\
$\mathrm{C}=\mathrm{O}$ & \\
\hline $\mathbf{N}$ & 48 \\
\hline $\mathrm{NH}_{2}$ & 52 \\
$\mathrm{C}-\mathrm{N}_{(\text {arom.) }}$ & \\
\hline $\mathbf{O}$ & 7 \\
$\mathrm{C}=\mathrm{O}$ & 51 \\
$\mathrm{O}-\mathrm{Si}$ & 42 \\
$\mathrm{C}-\mathrm{OH}$ & \\
\hline percentages refer to the atom in bold in each functional group.
\end{tabular}

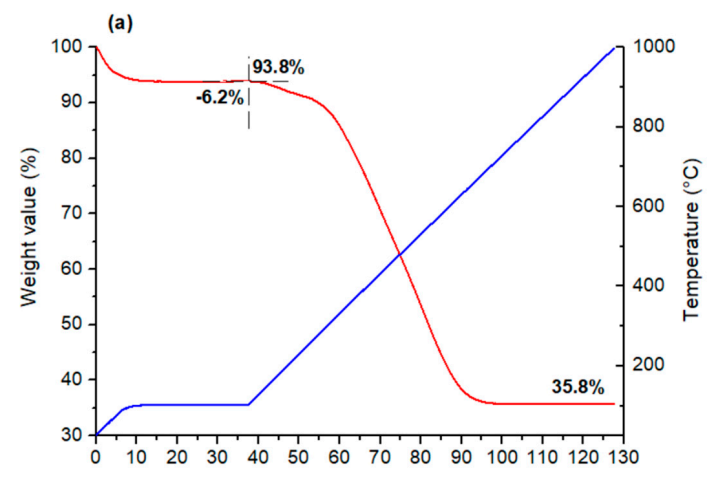

(a)

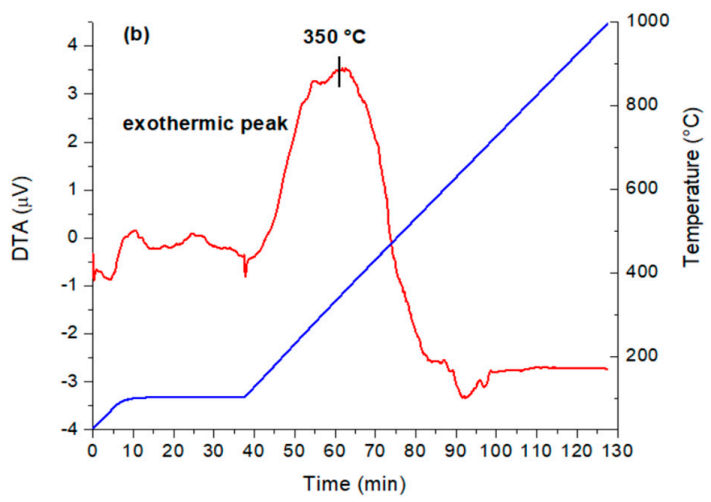

(b)

Figure 3. (a) Thermogravimetric (TG) and (b) Differential thermal analysis (DTA) curves of PolyCat-Si.

Thermogravimetric analysis of other preparations of PolyCat-Si (Figure S1) demonstrated the reproducibility of the synthesis.

Structural characteristics of the hybrid material were also investigated by monitoring its mobility in water through Dynamic Light Scattering (DLS). DLS measurements displayed the presence of a wide population with a hydrodynamic diameter of $411 \pm 98 \mathrm{~nm}$. Moreover, $\zeta$-potential measurements showed a negative surface charge $(-14.0 \pm 1.6 \mathrm{mV})$ in aqueous solution. By changing the $\mathrm{pH}$ of the medium, from 7.0 to 1.0, it was observed an increase in the dimensions of the PolyCat-Si $\left(D_{h}=1124 \pm 168 \mathrm{~nm}\right)$ and a positive surface charge as showed by the $\zeta$-potential value of $+30 \pm 2 \mathrm{mV}$. The latter value confirms the presence of terminal $-\mathrm{NH}_{2}$ groups which are protonated in acidic medium. Such $\zeta$-potential behavior closely resembles that of polydopamine [25-28].

Surface textural properties of the hybrid material were investigated by using $\mathrm{N}_{2}$ adsorption/ desorption measurements. In particular, the Brunauer-Emmett-Teller (BET) method [23] was applied for the calculation of the specific surface area (SSA); estimation of the pore volumes and pore size distributions was carried out with Barrett-Joyner-Halenda (BJH) method [24] using the desorption isotherm. Figure 4 displays the $\mathrm{N}_{2}$ adsorption/desorption isotherms that are of type IV and do not show any evident hysteresis loop except at relatively high pressure $0.9-1.0 \mathrm{p} / \mathrm{p}^{0}$. The SSA of the hybrid material was $63 \mathrm{~m}^{2} \cdot \mathrm{g}^{-1}$. 


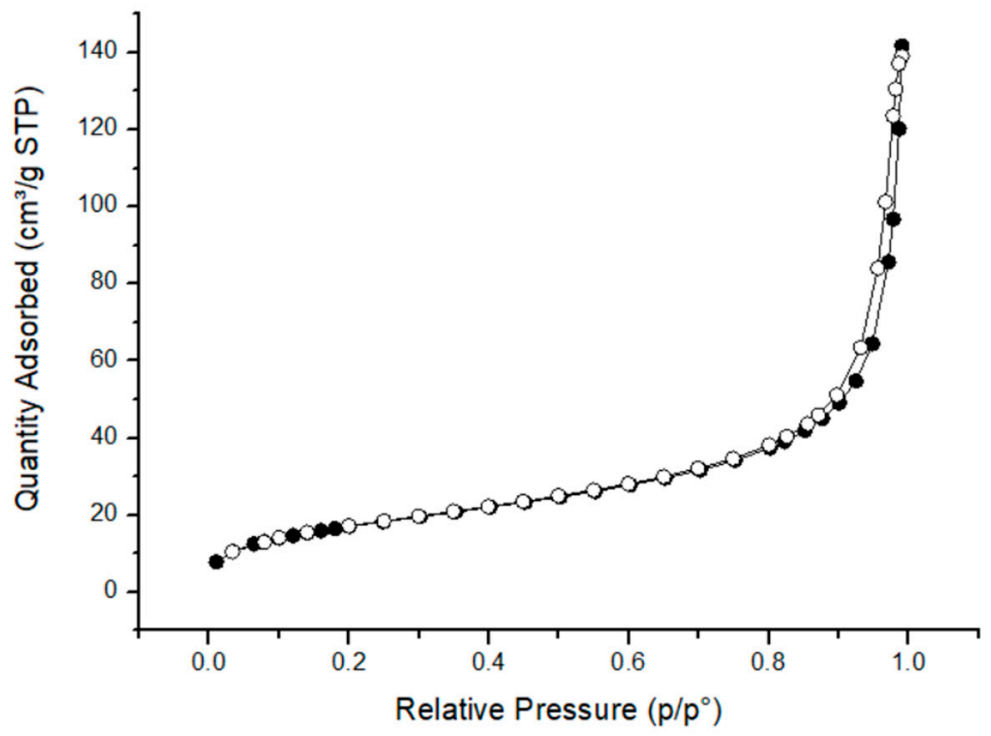

Figure 4. $\mathrm{N}_{2}$ adsorption/desorption isotherms of PolyCat-Si registered in the relative pressure range $\mathrm{p} / \mathrm{p}_{0}$ equal to $0-1.0$.

The pore size distribution reported in Figure $5 \mathrm{a}, \mathrm{b}$ indicates a wide distribution of pores in the entire range, $2-100 \mathrm{~nm}$, with the main contribution of mesopores between $2-10 \mathrm{~nm}$. The average pore size calculated by BJH model was equal to $7.4 \mathrm{~nm}$ with a cumulative volume of pores of $0.21 \mathrm{~cm}^{3} \cdot \mathrm{g}^{-1}$.
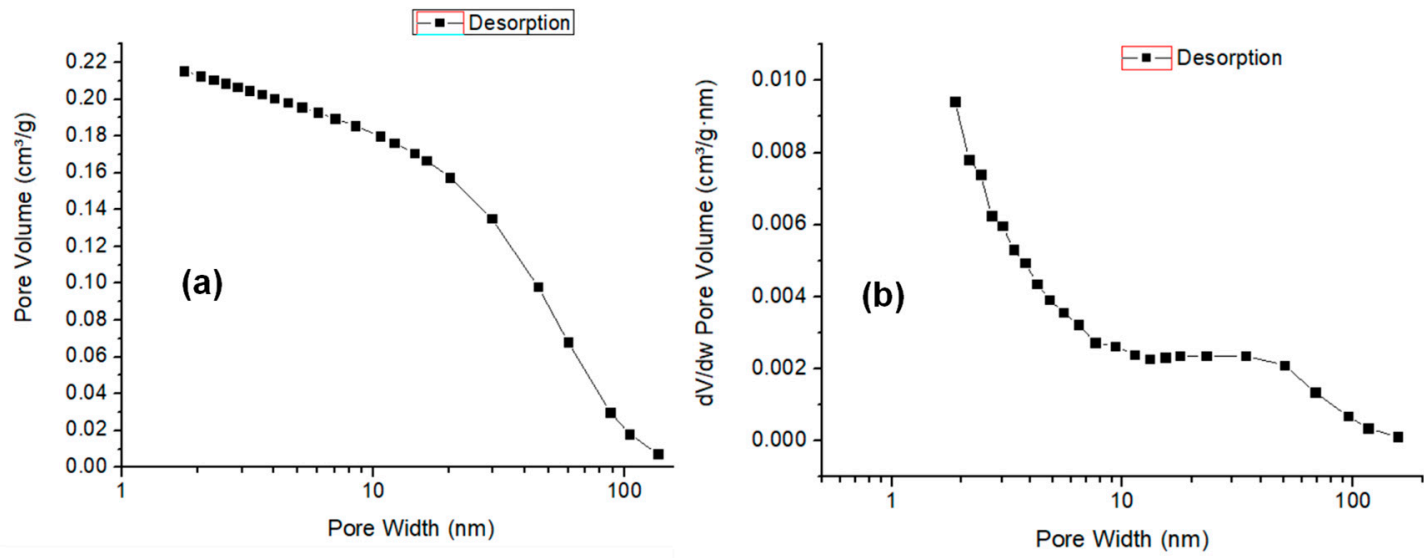

Figure 5. (a) Pore volume $\left(\mathrm{cm}^{3} / \mathrm{g}\right)$ vs. pore width $(\mathrm{nm})$ and $(\mathbf{b}) \mathrm{dV} / \mathrm{dw}$ Pore volume $\left(\mathrm{cm}^{3} / \mathrm{g} \cdot \mathrm{nm}\right)$ vs. pore width $(\mathrm{nm})$ calculated by Barrett-Joyner-Halenda $(\mathrm{BJH})$ model on the isotherm desorption branch of PolyCat-Si.

SEM investigations of PolyCat-Si (Figure 6) showed regular round-shaped nanostructures, typical of polidopamine-like materials, with dimensions in the nanometric range (ca. $70 \mathrm{~nm}$ ). In addition, EDS analysis showed the signals of silicon, oxygen, carbon, and nitrogen which further confirm the presence of these elements in the PolyCat-Si. 


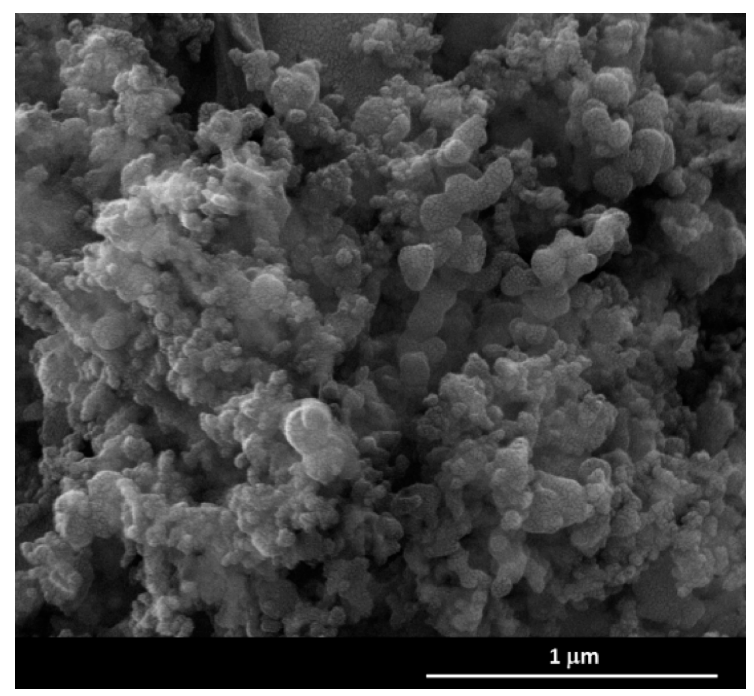

(a)

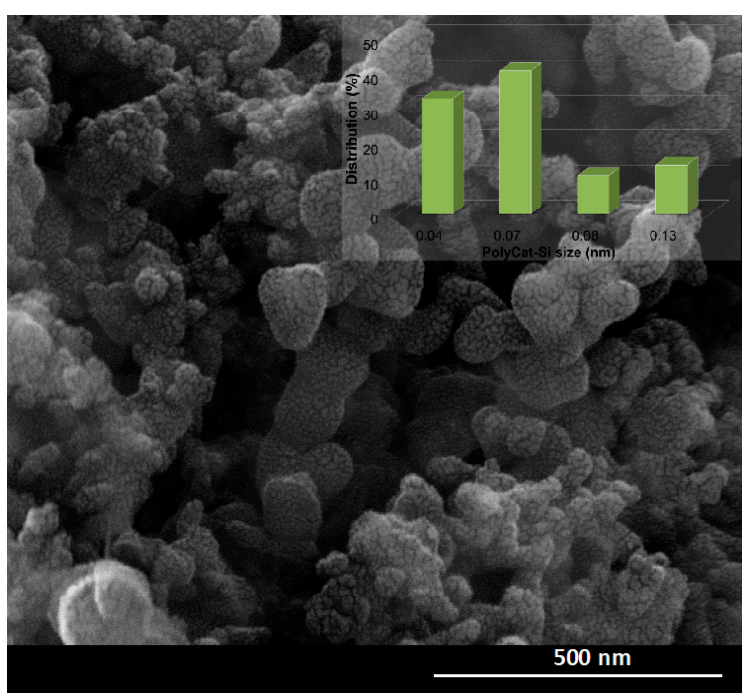

(b)

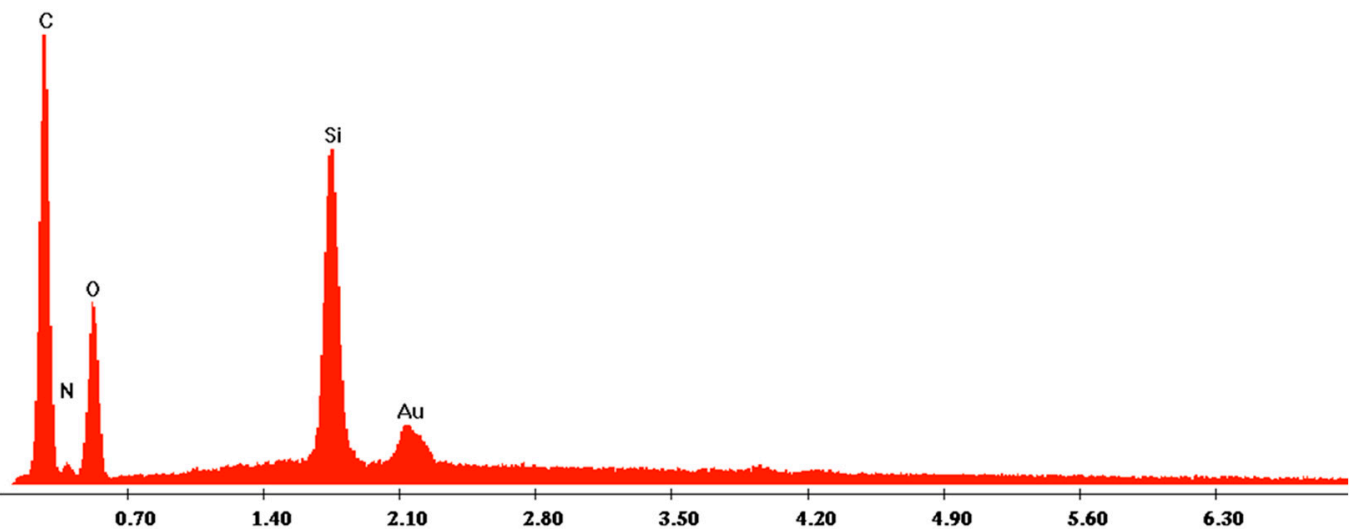

Energy (keV)

(c)

Figure 6. (a,b) SEM images of PolyCat-Si nanomaterial. The inset shows the PolyCat-Si size distribution ( $\mathrm{n}=50)$; (c) EDS pattern. Sample is coated with gold.

In order to assess the possible use of PolyCat-Si as potential system for dyes removal, adsorption experiments were performed. Therefore, we determined the adsorption capacity of PolyCat-Si for 11 anionic and cationic dyes (Figure 7a) at different $\mathrm{pH}$ values, namely, 1.0 and 7.4. The results showed that the PolyCat-Si was able to efficiently absorb anionic dyes, at both the $\mathrm{pH}$ values investigated. However, the acidic medium allowed for a better adsorption capacity of PolyCat-Si (Figure 7b). This behavior was explained taking into account the $\mathrm{pH}_{\mathrm{pzc}}$ of the nanomaterial. The determination of this value is crucial to highlight some alterations in the protonation-deprotonation characteristics of the surface of a material since it represents the point at which the surface acidic (or basic) functional groups no longer contribute to the $\mathrm{pH}$ value of the solution [29]. We found that the PolyCat-Si material possesses a $\mathrm{pH}_{\mathrm{PZC}}$ of ca. 8.7 (Figure 7c). Therefore, its surface in $\mathrm{pHs}$ lower than $\mathrm{pH}$ PZC shows a net positive charge, and thus, the nanomaterial could attract by electrostatic interactions the anionic dyes. However, most of the dyes investigated present $\mathrm{pK}_{\mathrm{a}}$ values in the $\mathrm{pH}$ range between 3 and 6 , so by increasing the $\mathrm{pH}$ (from 1.0 to 7.4), the dyes turn into their neutral form and the attractive forces decrease explaining the slight adsorption ability decrease at neutral $\mathrm{pH}$. 
<smiles>CCN(CC)c1ccc2c(c1)Oc1cc([NH+](CC)CC)ccc1/C2=C(\C)C(=O)O</smiles>

Rhodamine B

(1)<smiles>CN(C)c1ccc(C(O)(c2ccccc2)c2ccc(N(C)C)cc2)cc1</smiles>

Malachite Green Carbinol hydrochloride

(4)

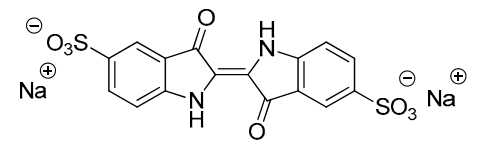

Indigo Carmine

(7)

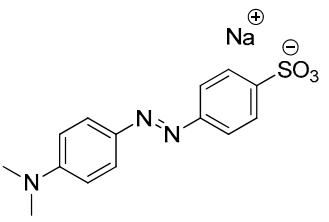

Methyl Orange

(2)

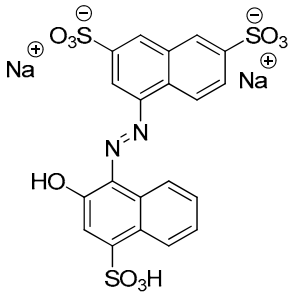

Hydroxy Naphtol Blue disodium salt

(5)<smiles></smiles>

Toluidine Blue

(8)

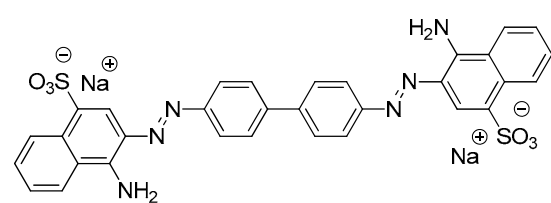

Congo Rubin

(3)

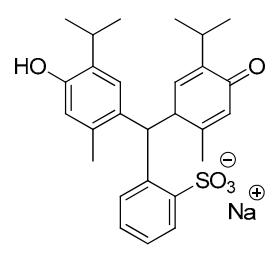

Thymol Blue

(6)

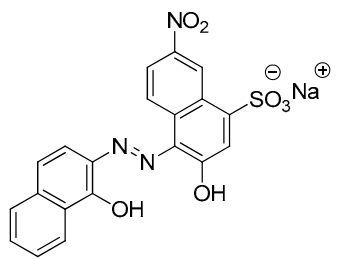

Eriochrome Black T

(9)

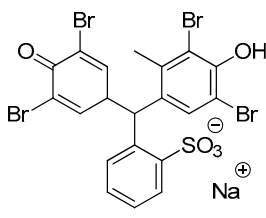

Bromocresol Green

(10)

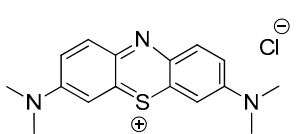

Methylene Blue

(11)

(a)

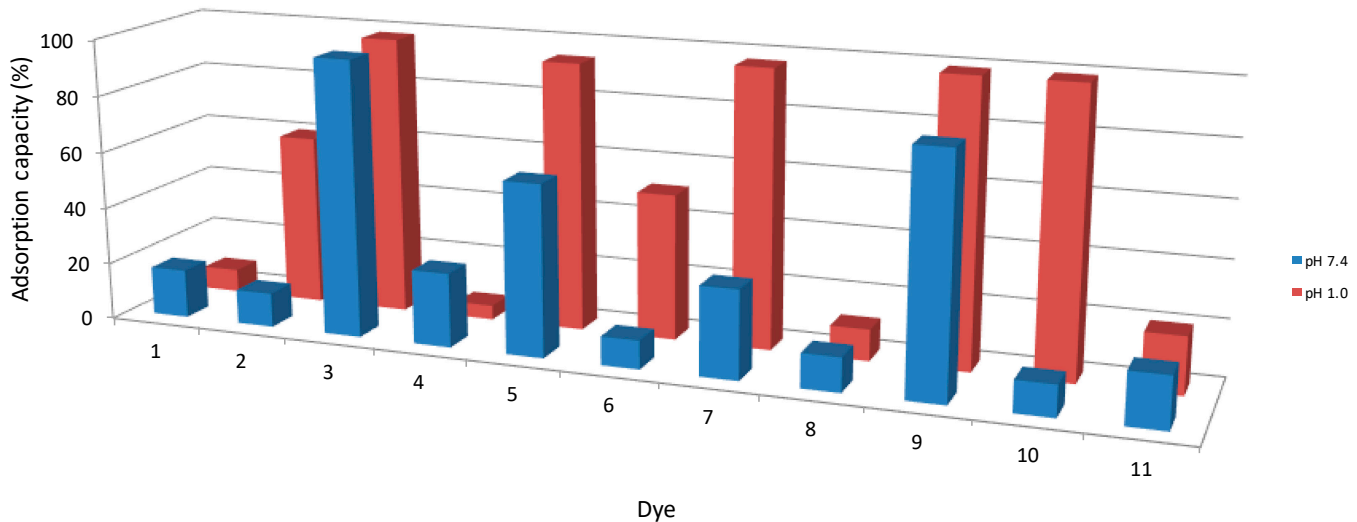

(b)

Figure 7. Cont. 


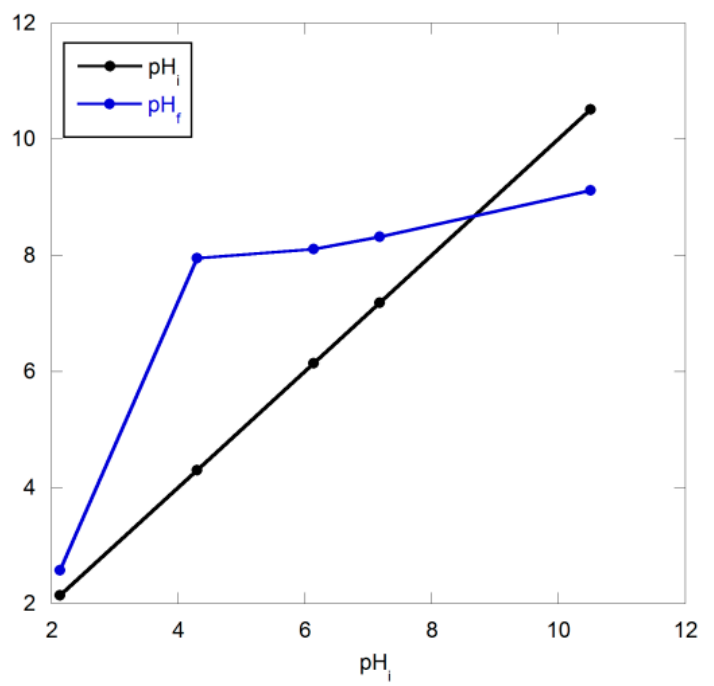

(c)

Figure 7. (a) Structure of the investigated anionic and cationic dyes; (b) adsorption capacities of PolyCat-Si for the investigated dyes at $\mathrm{pH} 1.0$ and 7.4 ; (c) determination of $\mathrm{pH}_{\mathrm{PZC}}$ for the PolyCat-Si.

Adsorption isotherm experiments were also carried out to evaluate the adsorption capacity of PolyCat-Si by choosing methyl orange (MO) as the dye model at $\mathrm{pH} 1.0(\mathrm{HCl} 0.1 \mathrm{~N})$. In Figure 8, the plot of the equilibrium amount of dye adsorbed into the hybrid material $\left(\mathrm{Qe}, \mathrm{mol} \cdot \mathrm{g}^{-1}\right) \mathrm{vs}$. the equilibrium dye concentration in solution $\left(\mathrm{Ce}, \mathrm{mol} \cdot \mathrm{L}^{-1}\right)$ was reported. Experimental data were analyzed by the using of the Langmuir and the Freundlich models. It was found that the adsorption data are only well fitted by the Langmuir equation $\left[\mathrm{Q}_{\mathrm{m}}=(3.4 \pm 0.3) \times 10^{-6} \mathrm{~mol} \cdot \mathrm{g}^{-1}, \mathrm{~K}_{\mathrm{L}}=(2.6 \pm 0.5) \times 10^{5} \mathrm{~L} \cdot \mathrm{mol}^{-1}\right]$, indicating that the adsorption follows the Langmuir adsorption isotherm, suggesting homogeneous nanocomposite and monomolecular layer adsorption.

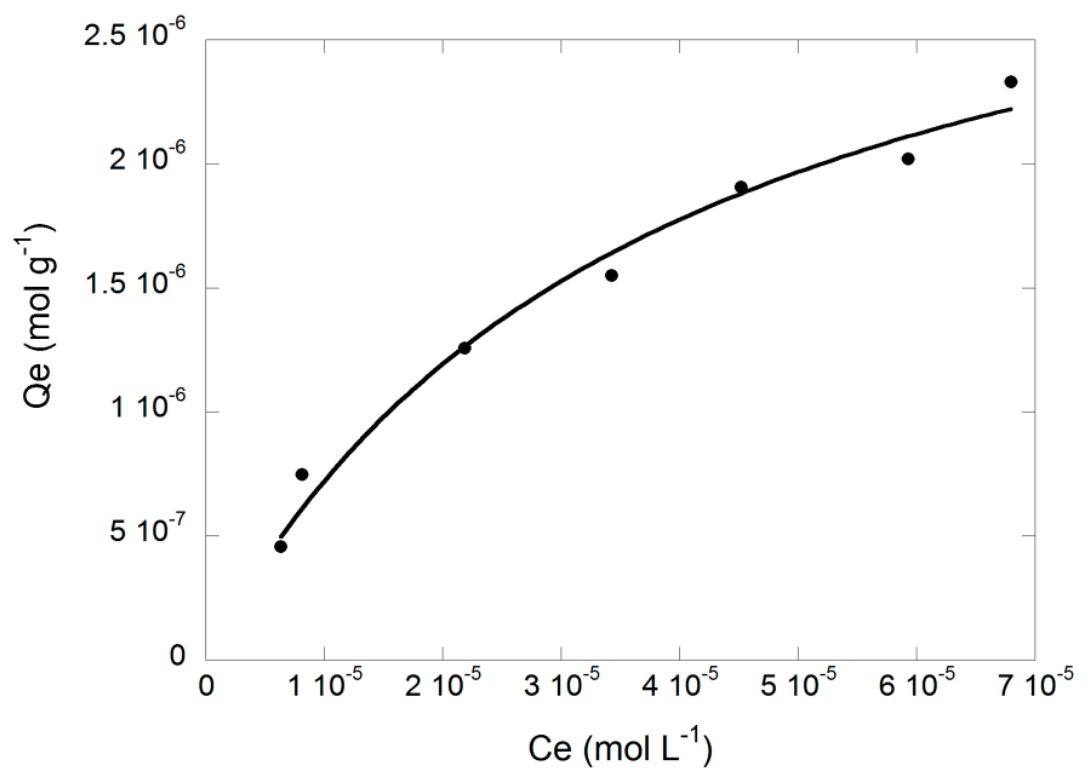

Figure 8. Adsorption isotherm of methyl orange (MO) on the hybrid material in $\mathrm{HCl} 0.1 \mathrm{~N}$ (results correspond to the mean \pm standard error mean of three independent assays).

To gain further insight into the adsorption mechanisms, the kinetics of methyl orange adsorption onto PolyCat-Si was also investigated (Figure S2). It was found the dye adsorption is a slow process and the equilibrium was reached only after $800 \mathrm{~min}$. The kinetic data were fitted by the Weber-Morris 
model and by a first-order kinetic model [1]. It was found that the kinetic data are better analyzed by a Weber-Morris model $\left(k=6.1 \pm 0.2 \mathrm{~min}^{-1} ; R^{2}=0.9857\right)$ indicating that the adsorption is ruled by an intra-particle diffusion.

The organic dye adsorbed onto the material can be easily removed by washing the PolyCat-Si with methanol, and therefore the material could be re-used.

It could be noteworthy to compare the adsorption performances of the PolyCat-Si towards anionic dyes (such as methyl orange, congo red, and so on) and those of other adsorbent materials already present in literature. PolyCat-Si in the best experimental conditions showed an adsorption capacity of $24 \mathrm{mg}^{-1}$ towards MO.

It should be noted that although our material possesses an adsorption capacity comparable with that of other polydopamine-like materials (Table 3), it possesses the great advantage to have free amino groups, which are available for further modifications which could improve the adsorption capacity of a post-modified PolyCat-Si material.

Table 3. Comparison of the adsorption capacity of other adsorbents towards $\mathrm{MO}$ in the previous studies at $298 \mathrm{~K}$.

\begin{tabular}{ccc}
\hline Material & $\mathbf{Q}_{\mathbf{e}} \mathbf{~} \mathbf{g} \cdot \mathbf{g}^{\mathbf{- 1}}$ & Ref. \\
\hline PDA-GO & 30 & {$[30]$} \\
Poly(catechol-tetraethylenepentamine-cyanuric & 37.2 & {$[31]$} \\
chloride)@hydrocellulose (PCEC-C) & 60.2 & {$[32]$} \\
PCL/PEO@PDA-45 & 2.1 & {$[33]$} \\
$\mathrm{Fe}_{3} \mathrm{O}_{4} @$ PDA NPs & almost zero & {$[34]$} \\
$\mathrm{PDA}_{\text {microspheres }}$ & 24 & this work \\
PolyCat-Si & & \\
\hline
\end{tabular}

\section{Conclusions}

In conclusion, new mussel inspired polydopamine-like silica-based material based on catechol and APTS (PolyCat-Si) was successful synthetized and characterized by several techniques that highlighted the presence of several functional groups (FT-IR, solid state NMR, EDX, TPD-CO ${ }_{2}$, and XPS). Furthermore, the textural properties, the thermal stability and mobility in aqueous regime were also investigated (BET, TGA, DLS, and $\zeta$-potential measurements). The morphology of the PolyCat-Si was imaged by SEM investigations. In addition, it was found that PolyCat-Si presented dimensions in the nanometric range. The potential feasibility of the PolyCat-Si hybrid material as a decontaminant of wastewater was investigated by studying its adsorption ability towards 11 anionic and cationic organic dyes. The ionicity of the material and the $\mathrm{pK}_{\mathrm{a}}$ values of the dyes were taken into account to explain the adsorption capacity of PolyCat-Si. The obtained results showed a promising application of the PolyCat-Si hybrid material in the bioremediation field.

Supplementary Materials: The following are available online at http:/www.mdpi.com/2079-4991/10/7/1416/s1. Experimental details Figure S1: Thermogravimetric curve of PolyCat-Si ( ${ }^{\text {nd }}$ preparation as example), Figure S2: Kinetic adsorption of MO on PolyCat-Si in $\mathrm{HCl} 0.1 \mathrm{~N}$.

Author Contributions: Conceptualization, S.R. and M.G.; methodology, M.M., V.C., C.V.I., M.S.-P., and L.F.L.; investigation, M.M., V.C., C.V.I., M.S.-P., and L.F.L.; data curation, M.M., V.C., C.V.I., M.S.-P., and L.F.L.; writing-original draft preparation, M.M. and V.C.; writing—review and editing, S.R. and M.G.; supervision, S.R. and M.G. project administration, S.R. and M.G.; funding acquisition, L.F.L. and M.G. All authors have read and agreed to the published version of the manuscript.

Funding: This research received no external funding.

Acknowledgments: The work was financially supported by the University of Palermo and was carried out in the frame of the PRIN2017- 2017YJMPZN project. The authors would thank Giuseppe Cavallaro (University of Palermo) for DLS and ל-potential measurements, Alberto Spinella (ATeN Center, UniPa) for solid state NMR measurements and Nunzio Gallì (ISMN-CNR) for specific surface area and porosity measurements.

Conflicts of Interest: The authors declare no conflict of interest. 


\section{References}

1. Massaro, M.; Armetta, F.; Cavallaro, G.; Chillura Martino, D.F.; Gruttadauria, M.; Lazzara, G.; Riela, S.; d'Ischia, M. Effect of halloysite nanotubes filler on polydopamine properties. J. Colloid Interface Sci. 2019, 555, 394-402. [CrossRef] [PubMed]

2. Zhu, G.; Gao, T.; Si, S.; Zhang, Z.; Liu, Q.; Zhou, G. Mussel-inspired polymerization of catechol and 1,6-hexamethylenediamine for material-independent surface chemistry. Appl. Surf. Sci. 2020, 507, 145080. [CrossRef]

3. Zhou, F.; Luo, J.; Song, S.; Wan, Y. Nanostructured polyphenol-mediated coating: A versatile platform for enzyme immobilization and micropollutant removal. Ind. Eng. Chem. Res. 2020, 59, 2708-2717. [CrossRef]

4. Wang, H.; Wu, J.; Cai, C.; Guo, J.; Fan, H.; Zhu, C.; Dong, H.; Zhao, N.; Xu, J. Mussel inspired modification of polypropylene separators by catechol/polyamine for Li-ion batteries. ACS Appl. Mater. Interface 2014, 6, 5602-5608. [CrossRef] [PubMed]

5. Iacomino, M.; Paez, J.I.; Avolio, R.; Carpentieri, A.; Panzella, L.; Falco, G.; Pizzo, E.; Errico, M.E.; Napolitano, A.; Del Campo, A.; et al. Multifunctional thin films and coatings from caffeic acid and a cross-linking diamine. Langmuir 2017, 33, 2096-2102. [CrossRef] [PubMed]

6. Long, Y.; Xiao, L.; Cao, Q. Co-polymerization of catechol and polyethylenimine on magnetic nanoparticles for efficient selective removal of anionic dyes from water. Powder Technol. 2017, 310, 24-34. [CrossRef]

7. Yang, J.; Saggiomo, V.; Velders, A.H.; Cohen Stuart, M.A.; Kamperman, M. Reaction pathways in catechol/primary amine mixtures: A window on crosslinking chemistry. PLoS ONE 2016, 11, e0166490. [CrossRef]

8. Lin, Z.; Luo, S.; Xu, D.; Liu, S.; Wu, N.; Yao, W.; Zhang, X.; Zheng, L.; Lin, X. Silica-polydopamine hybrids as light-induced oxidase mimics for colorimetric detection of pyrophosphate. Analyst 2020, 145, 424-433. [CrossRef]

9. Silvestri, B.; Vitiello, G.; Luciani, G.; Calcagno, V.; Costantini, A.; Gallo, M.; Parisi, S.; Paladino, S.; Iacomino, M.; D'Errico, G.; et al. Probing the eumelanin-silica interface in chemically engineered bulk hybrid nanoparticles for targeted subcellular antioxidant protection. ACS Appl. Mater. Interfaces 2017, 9, 37615-37622. [CrossRef]

10. Wang, Z.; Han, M.; Zhang, J.; He, F.; Xu, Z.; Ji, S.; Peng, S.; Li, Y. Designing preferable functional materials based on the secondary reactions of the hierarchical tannic acid (TA)-aminopropyltriethoxysilane (APTES) coating. Chem. Eng. J. 2019, 360, 299-312. [CrossRef]

11. Chen, F.; Xing, Y.; Wang, Z.; Zheng, X.; Zhang, J.; Cai, K. Nanoscale polydopamine (pda) meets $\pi-\pi$ interactions: An interface-directed coassembly approach for mesoporous nanoparticles. Langmuir 2016, 32, 12119-12128. [CrossRef] [PubMed]

12. Tran, N.T.; Flanagan, D.P.; Orlicki, J.A.; Lenhart, J.L.; Proctor, K.L.; Knorr, D.B. Polydopamine and polydopamine-silane hybrid surface treatments in structural adhesive applications. Langmuir 2018, 34, 1274-1286. [CrossRef]

13. Fu, Y.; Cai, M.; Zhang, E.; Cao, S.; Ji, P. A novel hybrid polymer network for efficient anticorrosive and antibacterial coatings. Ind. Eng. Chem. Res. 2016, 55, 4482-4489. [CrossRef]

14. Demey, H.; Barron-Zambrano, J.; Mhadhbi, T.; Miloudi, H.; Yang, Z.; Ruiz, M.; Sastre, A.M. Boron removal from aqueous solutions by using a novel alginate-based sorbent: Comparison with $\mathrm{Al}_{2} \mathrm{O}_{3}$ particles. Polymers 2019, 11, 1509. [CrossRef] [PubMed]

15. Attar, K.; Demey, H.; Bouazza, D.; Sastre, A.M. Sorption and desorption studies of Pb(II) and Ni(II) from aqueous solutions by a new composite based on alginate and magadiite materials. Polymers 2019, 11, 340. [CrossRef] [PubMed]

16. Boudaoud, N.; Miloudi, H.; Bouazza, D.; Adjdir, M.; Tayeb, A.; Fortuny, A.; Demey, H.; Sastre, A.M. Removal of zinc from aqueous solutions using lamellar double hydroxide materials impregnated with cyanex 272: Characterization and sorption studies. Molecules 2020, 25, 1263. [CrossRef] [PubMed]

17. Liu, Y.; Ai, K.; Lu, L. Polydopamine and its derivative materials: Synthesis and promising applications in energy, environmental, and biomedical fields. Chem. Rev. 2014, 114, 5057-5115. [CrossRef]

18. Yang, J.; Cohen Stuart, M.A.; Kamperman, M. Jack of all trades: Versatile catechol crosslinking mechanisms. Chem. Soc. Rev. 2014, 43, 8271-8298. [CrossRef]

19. Haemers, S.; Koper, G.J.M.; Frens, G. Effect of oxidation rate on cross-linking of mussel adhesive proteins. Biomacromolecules 2003, 4, 632-640. [CrossRef] 
20. Boukoussa, B.; Hakiki, A.; Bouazizi, N.; Beltrao-Nunes, A.-P.; Launay, F.; Pailleret, A.; Pillier, F.; Bengueddach, A.; Hamacha, R.; Azzouz, A. Mesoporous silica supported amine and amine-copper complex for $\mathrm{CO}_{2}$ adsorption: Detailed reaction mechanism of hydrophilic character and $\mathrm{CO}_{2}$ retention. J. Mol. Struct. 2019, 1191, 175-182. [CrossRef]

21. Ghomari, K.; Benhamou, A.; Hamacha, R.; Bengueddach, A.; Nousir, S.; Shiao, T.C.; Roy, R.; Azzouz, A. TPD and DSC insights in the basicity of MCM-48-like silica and modified counterparts. Thermochim. Acta 2015, 600, 52-61. [CrossRef]

22. Hakiki, A.; Boukoussa, B.; Habib Zahmani, H.; Hamacha, R.; Hadj Abdelkader, N.e.H.; Bekkar, F.; Bettahar, F.; Nunes-Beltrao, A.P.; Hacini, S.; Bengueddach, A.; et al. Synthesis and characterization of mesoporous silica SBA-15 functionalized by mono-, di-, and tri-amine and its catalytic behavior towards michael addition. Mater. Chem. Phys. 2018, 212, 415-425. [CrossRef]

23. Yue, M.B.; Chun, Y.; Cao, Y.; Dong, X.; Zhu, J.H. $\mathrm{CO}_{2}$ capture by as-prepared SBA-15 with an occluded organic template. Adv. Funct. Mater. 2006, 16, 1717-1722. [CrossRef]

24. Oubaha, M.; Dubois, M.; Murphy, B.; Etienne, P. Structural characterisation of a sol-gel copolymer synthesised from aliphatic and aromatic alkoxysilanes using ${ }^{29}$ Si-NMR spectroscopy. J. Sol-Gel Sci. Technol. 2006, 38, 111-119. [CrossRef]

25. Wang, Z.; Guo, J.; Ma, J.; Shao, L. Highly regenerable alkali-resistant magnetic nanoparticles inspired by mussels for rapid selective dye removal offer high-efficiency environmental remediation. J. Mater. Chem. A 2015, 3, 19960-19968. [CrossRef]

26. Zhang, Q.; Li, Y.; Yang, Q.; Chen, H.; Chen, X.; Jiao, T.; Peng, Q. Distinguished Cr(VI) capture with rapid and superior capability using polydopamine microsphere: Behavior and mechanism. J. Hazard. Mater. 2018, 342, 732-740. [CrossRef]

27. Wang, K.; Fu, J.; Wang, S.; Gao, M.; Zhu, J.; Wang, Z.; Xu, Q. Polydopamine-coated magnetic nanochains as efficient dye adsorbent with good recyclability and magnetic separability. J. Colloid Interface Sci. 2018, 516, 263-273. [CrossRef]

28. Fu, J.; Chen, Z.; Wang, M.; Liu, S.; Zhang, J.; Zhang, J.; Han, R.; Xu, Q. Adsorption of methylene blue by a high-efficiency adsorbent (polydopamine microspheres): Kinetics, isotherm, thermodynamics and mechanism analysis. Chem. Eng. J. 2015, 259, 53-61. [CrossRef]

29. Mahadwad, O.K.; Parikh, P.A.; Jasra, R.V.; Patil, C. Photocatalytic degradation of reactive black-5 dye using $\mathrm{TiO}_{2}$ impregnated ZSM-5. Bull. Mater. Sci. 2011, 34, 551-556. [CrossRef]

30. Dong, Z.; Wang, D.; Liu, X.; Pei, X.; Chen, L.; Jin, J. Bio-inspired surface-functionalization of graphene oxide for the adsorption of organic dyes and heavy metal ions with a superhigh capacity. J. Mater. Chem. A 2014, 2, 5034-5040. [CrossRef]

31. Liu, Q.; Liu, Q.; Wu, Z.; Wu, Y.; Gao, T.; Yao, J. Efficient removal of methyl orange and alizarin red s from $\mathrm{pH}$-unregulated aqueous solution by the catechol-amine resin composite using hydrocellulose as precursor. ACS Sustain. Chem. Eng. 2017, 5, 1871-1880. [CrossRef]

32. Wang, C.; Yin, J.; Wang, R.; Jiao, T.; Huang, H.; Zhou, J.; Zhang, L.; Peng, Q. Facile preparation of self-assembled polydopamine-modified electrospun fibers for highly effective removal of organic dyes. Nanomaterials 2019, 9, 116. [CrossRef] [PubMed]

33. Zhou, Z.; Liu, R. $\mathrm{Fe}_{3} \mathrm{O}_{4} @$ polydopamine and derived $\mathrm{Fe}_{3} \mathrm{O}_{4} @$ carbon core-shell nanoparticles: Comparison in adsorption for cationic and anionic dyes. Colloids Surf. Physicochem. Eng. Asp. 2017, 522, 260-265. [CrossRef]

34. Fu, J.; Xin, Q.; Wu, X.; Chen, Z.; Yan, Y.; Liu, S.; Wang, M.; Xu, Q. Selective adsorption and separation of organic dyes from aqueous solution on polydopamine microspheres. J. Colloid Interface Sci. 2016, 461, 292-304. [CrossRef] [PubMed]

(C) 2020 by the authors. Licensee MDPI, Basel, Switzerland. This article is an open access article distributed under the terms and conditions of the Creative Commons Attribution (CC BY) license (http://creativecommons.org/licenses/by/4.0/). 